\title{
Inventariando o financiamento da Educação no período colonial e os
} primeiros indícios da educação profissional

\section{Inventorying the educacion financing at the colonial time and the first signs of professional education}

\section{Inventario del financiamiento de la educación em el período colonial y los primeros signos de la educación profesional}

\author{
Oliveira, Ramon Igor da Silveira ${ }^{1}$ (Natal, RN, Brasil) \\ ORCID ID: http://orcid.org/0000-0002-8205-8614 \\ Ferreira, Maria Aparecida dos Santos² (São Paulo de Potengi, RN, Brasil) \\ ORCID ID: http://orcid.org/0000-0002-6213-8916
}

\section{Resumo}

Este trabalho objetiva inventariar as medidas adotadas para o financiamento da educação no Brasil Colônia e apontar os primeiros indícios da educação profissional. Como método, optou-se pelo materialismo histórico-dialético, aplicado à abordagem qualitativa e à pesquisa bibliográfica exploratória. Apurou-se que a educação obteve recursos de diversas fontes durante o seu curso no período colonial do Brasil, indo desde as doações até a criação de impostos específicos para o seu financiamento. Apontou-se também indícios de uma formação profissional, realçados em ocasiões nas quais os menos abastados recebiam o ensino de ofícios manuais em oficinas, em detrimento da formação escolarizada fornecida a aristocracia.

Palavras-chave: Financiamento da educação. Educação profissional. Brasil Colônia.

\begin{abstract}
This paper aims to list the measures taken for the financing of education in Colonial Brazil and to point out the first signs of professional education. As a method, historical-dialectical materialism was chosen, applying the qualitative approach and exploratory bibliographic research. It was discovered that education obtained resources from several sources during its course in the colonial period of Brazil, ranging from donations to the creation of specific taxes for its financing. The evidence of vocational training was also pointed out, highlighted on occasions in which the less affluent received teaching of manual crafts in workshops instead of formal education, provided to the aristocracy.
\end{abstract}

Keywords: Education financing. Professional education. Colonial Brazil.

\section{Resumen}

Este trabajo tiene como objetivo inventariar las medidas adoptadas para el financiamiento de la educación en el Brasil colonial y señalar los primeros signos de la educación profesional. Como método, optamos por el materialismo histórico-dialéctico, aplicado al enfoque cualitativo y la investigación exploratoria bibliográfica. Se descubrió que la educación obtuvo recursos de varias fuentes durante su curso en el período colonial de Brasil, desde donaciones hasta la creación de impuestos específicos para su financiamiento. También se señalaran las primeras indicaciones de una formación professional, destacada en ocasiones en que los menos ricos recibían la enseñanza de la artesania manual en talleres, en detrimento de la escolarización proporcionada a la aristocracia.

Palavras-Clave: Financiación de la educación. Educación professional. Colonia de Brasil.

\section{Introdução}

A importância de compreender como se deu o financiamento das políticas educacionais ao longo do tempo, bem como a relação entre essas políticas e os

\footnotetext{
1 Mestrando em Educação Profissional no Instituto Federal do Rio Grande do Norte - IFRN. ramonygor@hotmail.com

2 Docente do Instituto Federal de Educação, Ciência e Tecnologia do Rio Grande do Norte - Campus São Paulo do Potengi.maria.santos@ifrn.edu.br
} 
interesses políticos, econômicos, e sobretudo, educacionais, estabelece o estudo do financiamento da educação como um campo de grande relevância. Tal importância é ressaltada, especialmente, quando se considera o baixo número de pesquisas existentes.

Para Saviani (2019), a educação no Brasil Colonial se decompõe em três períodos distintos. O primeiro deles, denominado de "período heroico", vai de 1549 a 1599, e inicia-se com a chegada dos primeiros membros da Companhia de Jesus ao Brasil, os quais almejavam a catequização e a conversão dos povos nativos ao catolicismo. Compreendido entre os anos de 1599 a 1759, o segundo momento destaca-se pela implementação da educação escolar no Brasil. Dada à preeminência dos jesuítas na esfera educacional, estes passam a se responsabilizar também pela educação dos filhos dos colonos e demais membros da elite portuguesa. No último, correspondente aos anos entre 1759 a 1808, sobressai-se a expulsão dos jesuítas dos territórios de Portugal e as conseguintes reformas educacionais promovidas pelo Marquês de Pombal, influenciadas pelo movimento iluminista na Europa (SILVA; AMORIM, 2017).

De acordo com Ferreira (2014), os caminhos do financiamento da educação brasileira também podem se desmembrar em três diferentes momentos: no primeiro deles, o Estado se ausenta e a tarefa de financiar as atividades educacionais recai sobre os padres jesuítas. No segundo, dado após a expulsão dos padres dos domínios de Portugal, as Câmaras Municipais tornam-se as responsáveis pelo financiamento da educação. No terceiro, com o advento da Constituição Federal de 1934, entram em vigor estratégias de vinculação mínima de recursos, que, provenientes de impostos, são direcionados ao financiamento educacional. Por se tratar de um recorte do período Colonial do Brasil, esta pesquisa aborda somente os dois primeiros desses momentos.

No intuito de responder as nossas inquietações, partimos da seguinte questão norteadora: na trajetória histórica da educação, como se deu o seu financiamento no período colonial, e quais os primeiros indícios da educação profissional? Diante deste questionamento, buscamos, nesta pesquisa, inventariar as medidas adotadas pelos atores responsáveis para garantir o financiamento da educação no Brasil Colônia, apontando os primeiros indícios da educação profissional. 
Em busca de resposta às inquietações e objetivos definidos, optou-se pelo método do materialismo histórico-dialético, que "caracteriza-se pelo movimento do pensamento através da materialidade histórica da vida dos homens em sociedade" (PIRES, 1997, p. 83). Utilizou-se também, sobre a abordagem qualitativa, uma pesquisa bibliográfica exploratória, baseada nos trabalhos de estudiosos do financiamento da educação como Cury (2018), Monlevade (2012), Menezes (2005) e demais autores que analisaram a educação no contexto do Brasil Colônia, como Shignov Neto e Maciel (2018), Sangenis (2014), Morais e Oliveira (2012), entre outros pesquisadores.

Desse modo, o estudo se baseia nas demarcações propostas por Saviani (2019) para a educação no período colonial, e organiza-se em três diferentes sessões, que tomam como pontos de partida, respectivamente: a chegada dos jesuítas e o início das atividades educativas; a implementação e expansão da educação escolar jesuítica; e a expulsão dos jesuítas e as reformas Pombalianas. São inventariadas, em cada uma dessas sessões, as estratégias de financiamento da educação, sendo feitos também apontamentos acerca dos primeiros indícios da educação profissional.

\section{O período heroico e a primeira forma de financiamento das ações - doações e a redízima}

Antes da chegada dos portugueses, os indígenas brasileiros possuíam seus próprios processos educativos, pautados na sobrevivência. Estes garantiam, mesmo não envolvendo espaços físicos próprios ou o ensino de letras, a continuidade e a reprodução cultural dos povos (MONLEVADE, 2012). Ao explicar o chamado "comunismo primitivo", Saviani (1994) elucida como a educação dos primeiros homens se dava de maneira comunitária. Baseada no relacionamento com a terra e com os outros, estes educavam, a partir destes processos produtivos, a si e aos seus descendentes.

Assim, os fenômenos educacionais se dão em paridade com necessidades imperativas ao desenvolvimento do modelo produtivo em voga, sendo, portanto, dependentes do contexto da realidade social e do momento histórico no qual se inserem (SHIGUNOV NETO; MACIEL, 2008). O processo que deu início à educação escolar no Brasil, no período Colonial, não ocorreu de forma diferente. 
No século $X V$, quando ainda se encontrava na posição de Colônia de Portugal, o Brasil tinha como principal propósito assistir a metrópole. Tendo seus recursos naturais explorados e exportados, a cana-de-açúcar era o produto de maior cultivo em seu território, sendo amplamente aprovada pela população europeia. $\mathrm{Na}$ época, o país era dividido por meio de Capitanias Hereditárias, um sistema que posteriormente mostrou-se frustrado, em grande parte devido aos constantes ataques de indígenas (NASCIMENTO, 2007).

Com a subsequente instalação de governos-gerais por Portugal, processo decorrido da queda do sistema de Capitanias, iniciaram-se as ações para o estabelecimento de uma educação escolar no Brasil. Essas ações foram principiadas pela chegada do Padre Manoel da Nóbrega, da Companhia de Jesus, em 1549 (SILVA, 2015). De origem parisiense, a Companhia instituída em 1534 por Inácio de Loyola dedicava-se à educação e à catequese e teve, a pedido de Dom João III, seis de seus membros enviados ao país, junto ao governador-geral Tomé de Souza (NASCIMENTO, 2007).

Estabelecida pelo grupo religioso dos Jesuítas com o apoio da Coroa Portuguesa, a implementação de uma educação escolar no Brasil era incumbida de duas principais missões: uma delas era a de opor-se ao Protestantismo, frente religiosa que ganhava força na Europa, a partir da conversão de novos adeptos do catolicismo. Para além, buscava-se executar o plano colonialista português, que visava subverter a hostilidade indígena e transformá-los em força para o trabalho (SILVA et al., 2016).

Cultivar, além de novos aderentes à fé católica, a mão de obra necessária para a continuidade da exploração de terras, fez com que houvesse um acordo de mútuo interesse para a Companhia de Jesus e para o Estado Português. Para alcançar estes objetivos, o foco da Companhia se apoiava sob o ensino das letras e da catequização de crianças nativas, uma vez que "nelas ainda não estavam enraizados os hábitos e costumes da cultura indígena" (NASCIMENTO, 2007, p. 185).

Buscava-se, assim, alinhar os indígenas ao arquétipo da civilização europeia, adaptando-os a rotinas de trabalho contínuo e infundindo nas tribos uma transformação cultural, vinculando seus processos de produção à acumulação e não mais à sobrevivência (SHIGUNOV NETO; MACIEL, 2008). Desse modo, mesmo ocupando a função de educadores, os padres jesuítas não buscavam educar os índios 
brasileiros, mas sim torná-los suscetíveis aos serviços da Coroa (NASCIMENTO, 2007). Logo, o modelo educativo implementado no país pela Companhia foi pensado e gerido não a partir do viés emancipatório de formar cidadãos autônomos, mas no propósito de obter lucro através de sua força produtiva (SILVA et al., 2016).

É necessário salientar que, de acordo com estudos de Shigunov Neto e Maciel (2008), foram muitas as ordens religiosas a operarem no território da Colônia brasileira. Essas ordens, porém, além de desembarcarem após a Companhia de Jesus, não tinham a educação como seu fundamento central. $O$ destaque dos jesuítas se deu, portanto, por sua proposta educativa, que colaborou de forma vital para que o Estado Português viesse a conquistar os objetivos de povoar e colonizar as terras brasileiras.

De natureza mendicante, os recursos previstos para o financiamento das missões promovidas pela Companhia de Jesus provinham principalmente de esmolas. Desse modo, para garantir a subsistência dos padres e dar início às práticas em solo brasileiro, a Companhia contou com doações da corte portuguesa, de modo que "a Coroa consignava uma verba mensal de um cruzado para o sustento de cada missionário, fornecia víveres e apoiava a construção de templos, residências e colégios" (SANGENIS, 2014, p. 32).

Eram, portanto, fornecidas duas verbas para a rede educacional jesuítica: uma delas, providenciada pelo Rei em uma única parcela, era destinada à construção das instalações educacionais e a sua equipagem; a outra, materializada na forma de uma pequena quantia em espécie, era enviada mensalmente e conferia a permanência dos religiosos (MENEZES, 2005).

Inicialmente, os padres jesuítas adotaram, como estratégia para a catequização dos indígenas, a construção de igrejas próximas aos perímetros das aldeias, as quais visitavam periodicamente. Em seguida, para a instrução das primeiras letras, utilizaram como tática o aldeamento, erguendo aldeias próprias para a habitação conjunta entre os missionários e os nativos. Tendo em vista não somente a doutrinação, o aldeamento também se fez necessário para separar e proteger os nativos dos portugueses, que mantinham condutas desaprovadas pelo Padre Nóbrega (COSTA; MENEZES, 2009). As chamadas "casas de bê-a-bá", construídas pelos próprios padres, tratavam-se de estruturas rústicas e materialmente limitadas (FERREIRA JR.; BITTAR, 2012). 
Apesar de ter a disseminação da religião como principal propósito, a Companhia de Jesus, motivada pela simples necessidade de mão de obra, essencial para a construção de instalações e a rápida produção de alimentos, acabou por introduzir o esboço primitivo de uma formação profissionalizante ao contexto educativo do Brasil Colonial (MORAIS, 2016). Assim, os nativos passavam também pelo ensino de ofícios manuais, aprendendo, não à toa, artes mecânicas que serviriam, posteriormente, aos propósitos dos jesuítas (MESQUIDA, 2013). Dentre estes ofícios, Alegre (2014, p. 91) destaca os de "carpinteiro, ferreiro, sapateiro, pedreiro".

Diferentemente do que se testemunha na educação profissional desenvolvida nos dias de hoje, a oferta dos padres jesuítas não seguia qualquer plano sistematizado de ensino, carecendo, portanto, de conhecimentos teóricos. Ela se dava principalmente através da observação: os aprendizes seguiam os padres até às oficinas, onde praticavam as artes manuais a serem aprendidas (MORAIS, 2016).

O vínculo entre os padres e os nativos acabou por convertê-los em preciosos ajudantes da Companhia. Para conquistar a salvação prometida pelos católicos, que viria não somente através da fé cristã, mas também pelo trabalho manual, os indígenas passaram a auxiliar na manutenção e edificação de casas, colégios, e até mesmo na proteção das propriedades jesuíticas, evitando invasões (MESQUIDA, 2013).

Entre as práticas metodológicas seguidas pelos padres, tanto para a conversão religiosa quanto para o ensino das primeiras letras aos indígenas, estavam técnicas das mais diversas. Dentre elas, Silva e Amorim (2017) citam "representações teatrais, cânticos e música instrumental, catecismo dialogados e a memorização pela repetição" (p. 191), métodos que se mostraram apropriados para atingir as crianças nativas.

A instrução das primeiras letras se mostrou um passo basal para o processo de doutrinação, uma vez que os índios precisavam de habilidades de leitura não somente para acessar os ensinamentos presentes nas escrituras da Companhia, mas para ajustar-se aos moldes de uma civilização letrada (MESQUIDA, 2013).

Ferreira Jr. \& Bittar (2012) apontam que, para isso, porém, foi necessário romper os limites impostos pela linguagem, barreira ultrapassada somente após 
gramaticarem a língua Tupi, "tarefa iniciada por Juan Azpilcueta Navarro e concluída por José de Anchieta" (p. 697).

Contendo a maior população de origem portuguesa, a cidade de Salvador foi a primeira a ganhar uma escola primária conduzida pelos padres jesuítas (MONLEVADE, 2012). Até então, instituições escolares eram inexistentes e o analfabetismo uma regra entre os povos da colônia. Tal postura era estratégica, e partia do interesse do Estado em obter o domínio ideológico sobre a população (SOUSA; SALES, 2018).

Fundada logo após a chegada da Companhia, a Escola da Bahia foi posteriormente batizada como Colégio dos Meninos de Jesus, e veio a se tornar a instituição escolar mais prestigiada do Brasil (LORENZ, 2018). Para a sua construção, o governador-geral Tomé de Sousa conferiu aos jesuítas, em 1550, uma sesmaria inicial, chamada "Água dos Meninos" (SANGENIS, 2014).

Ainda que a Companhia de Jesus contasse com doações de colonos e com o suporte financeiro da Corte, "nem sempre se obtinham os recursos suficientes para uma mais rápida expansão das atividades missionárias" (SANGENIS, 2014, p. 33). Em vista disso, em 1564, o Rei Dom Sebastião I determinou, através de um alvará régio, a existência de um subsídio financeiro para o Colégio situado na Bahia (FERREIRA JR.; BITTAR, 2012).

Chamada redízima, a fonte de financiamento provinha de uma fração retirada da dízima, tributo que retinha dez por cento sobre os valores das mercadorias exportadas (MONLEVADE, 2012). Foi estabelecido por D. Sebastião I, no referido documento, que:

[...] eu e os reis destes reinos meus subcessores, governadores e perpetuos administradores [...] vendo quam apropriado o Instituto dos Padres da Companhia de Jesus he para a conversão dos infieis e gentios daquellas partes e instrução dos novamente convertidos, ter mandado alguns dos ditos Padres as ditas partes do Brasil cõ intenção e determinação de nellas mandar fazer e fundar collegios a custa da sua fazenda [...]. E depois de avida a dita informação, assentey cõ parecer dos do meu cõselho, de mandar acabar nas ditas partes hum collegio da dita Companhia na cidade do Salvador da capitania da Baya de todos os Santos, onde já está começado; [...] e pera sostentação do dito collegio e religiosos delle ey por bê de lhes aplicar e dotar, e de feito por esta minha carta de doação doto e aplico huma redizima de todos os dizimos e direitos que tenho e me pertencem e ao diante pertencerem nas ditas partes do Brasil (D. Sebastião I, 1938, p. 538-539 apud FERREIRA JR.; BITTAR, 2012, p. 695). 
Programa de Pós-graduação em Educação, Universidade Federal do Ceará Fortaleza-CE-Brasil

Advindo prioritariamente de impostos sobre o açúcar (CURY, 2018), a redízima, apesar de permitir a inicial expansão da rede de ensino jesuítica, logo se mostrou não apenas insatisfatória, mas também inconsistente (MENEZES, 2005).

\section{Expansão da Educação Escolar - autofinanciamento da rede jesuítica}

Com o financiamento oficial da Coroa, os padres jesuítas, além da tarefa de doutrinar os indígenas, foram incumbidos de oferecer educação aos filhos dos colonos, membros da classe dominante portuguesa (SILVA et al., 2016). Desse modo, os esforços para fundar os colégios que viriam a atender os descendentes da nobreza iniciaram-se nos anos 60 do século XVI (CURY, 2018). Assim, no decorrer deste século, a Companhia de Jesus desenvolveu, em paralelo com a catequização dos nativos, a implementação da educação escolar no Brasil Colonial (COSTA; MENEZES, 2009).

Com o substancial aumento no número de escolas e colégios jesuíticos ao redor do globo, número esse que, pelo ano de 1599 chegou a 245, cresceu também a necessidade de uma diretriz que determinasse o padrão de funcionamento desses espaços (LORENZ, 2018). Tal necessidade culminou na publicação do Ratio, um "método de ensino, que estabelecia o currículo, a orientação e a administração do sistema educacional a ser seguido" (SHIGUNOV NETO; MACIEL, 2008, p. 180).

Também conhecido como Ratio Studiorum, o documento publicado em 1599 instruía a regulamentação da rede educacional jesuítica através de uma lista de regras, que guiavam e organizavam diversas vertentes da instituição (LORENZ, 2018). Inspirando-se na cultura europeia, o método apresentava entre suas características "a centralização e o autoritarismo da metodologia, a orientação universalista, a formação humanista e literária" (SHIGUNOV NETO; MACIEL, 2008, p. 180). Assim, o manual buscava, prioritariamente, "conservar o indivíduo no quadro dos padrões da sociedade metropolitana" (MESQUIDA, 2013, p. 246).

Segundo Costa \& Menezes (2009, p. 34), o Ratio Studiorum antevia três diferentes graus de ensino, sendo estes: "um elementar, chamado de curso de Humanidades; outro de formação superior, o de Filosofia ou Artes; e, por fim, o de formação profissional dos futuros padres, o curso de Teologia", primordial para a continuidade da Companhia. Alicerçado em uma Pedagogia Tradicional, o Ratio 
previa uma rígida disciplina, além de práticas que permitiam o exercício de habilidades como a retórica e a emulação.

Ao atender aqueles mais abastados em seus colégios, a estrutura de ensino dos jesuítas se dividiu, decompondo a educação em duas diferentes vertentes: a "escolarizada, humanista, livresca, para iluminar o espírito, afastada da ciência e das utilidades práticas - e o esboço de uma educação profissionalizante [...] bastante assistemática e não escolarizada" (MORAIS, 2016, p. 14).

Desse modo, nos colégios superiores era oferecido, aos filhos dos senhores do engenho, o ensino intelectualizado previsto pelo Ratio, e nas escolas inferiores, uma formação direcionada aos nativos, centrada na catequização e aprendizagem de ofícios (NASCIMENTO, 2007).

De acordo com Almeida (2014, p. 122-123), essa estratégia educacional revela o modo como a educação jesuítica "não atendia a todos da mesma forma, caracterizando um modelo de aprendizado excludente, pois os jesuítas acreditavam que cada pessoa deveria ser incumbida a um tipo de trabalho", a depender do espaço social que ocupava. Esse movimento segregacionista expõe as ambições pelo domínio da força de trabalho nativa, motivo por trás da implementação de uma educação destinada a estes povos.

Sousa e Sales (2018) apontam, em seus estudos, o modo como a doutrinação católica dos povos indígenas perdeu sua centralidade, dando espaço à formação intelectual da elite portuguesa, afirmando que:

\footnotetext{
No desenrolar do programa educativo dos jesuítas no Brasil, percebemos que a partir do século XVI este programa já não guarda mais aquele caráter preferencial pelo indígena, conferido pelo padre Manuel de Nóbrega. Pelo contrário, o sistema educativo da Companhia se afasta desta linha e passa a se preocupar com uma clientela da elite, oriunda da aristocracia dos engenhos, da pequena burguesia do século XVI e dos donos da mineração do século XVIII. Os colégios são, então, construídos para atender à elite e preparar o quadro dirigente da vida pública colonial (SOUSA; SALES, 2018, p. 100-101).
}

Assim, os padres jesuítas tiveram três de seus colégios fundados com o financiamento da Coroa portuguesa, sendo estes o já citado Colégio da Bahia, que veio a receber investimentos da Corte a partir de 1564, o Colégio do Rio de Janeiro, fundado em 1567, e o Colégio de Pernambuco, em 1576 (COSTA; MENEZES, 2009). 
De acordo com Vianna (1945), para custear a edificação dos colégios, os jesuítas receberam a ordem de 166 cruzados.

Com gastos crescentes e a iminente insuficiência dos recursos provenientes da redízima, o Padre Manoel da Nóbrega, visando garantir a continuidade das atividades e a expansão da rede educativa, elaborou, com 0 respaldo das Constituições da Companhia de Jesus, um novo plano de autofinanciamento (MONLEVADE, 2012).

Formuladas por Inácio de Loyola, que foi escolhido pelos demais membros da Companhia de Jesus para o cargo de Superior Geral, as Constituições continham as diretrizes a serem seguidas pelos padres jesuítas (TOLEDO; RUCKSTADTER, 2002). De acordo com estas, os colégios eram as únicas instituições jesuíticas com permissão para "possuir bens que garantissem o sustento" (FÁVERO, 200, p. 93).

Desse modo, fazendo uso das sesmarias concedidas pela Corte para a construção dos colégios, os jesuítas passaram a arrotear as terras, transformando-as em fazendas e comercializando o que se excedia, vendendo principalmente mandioca e gado. Devido ao impedimento de padres empenharem-se na agricultura, Nóbrega solicitou, em carta endereçada ao Rei Dom João III no dia 14 de setembro de 1551 (SANGENIS, 2014), o envio de "alguns escravos da Guiné para que trabalhassem nas roças de mantimentos e algodão" (VIANNA, 1945, p. 374).

Assim, partindo da obtenção de terras, cabeças de gado e até mesmo de escravos, os padres jesuítas passaram a lucrar a partir de atividades econômicas próprias. Graças a uma competente tática de condução, que consistia em reinvestir os rendimentos na ampliação das fazendas, os padres rapidamente ampliaram seu capital (MENEZES, 2005).

Localizada no Rio de Janeiro, a Fazenda de Santa Cruz, uma das sete que tinham os jesuítas como proprietários, alcançou, de acordo com Sangenis (2014), o número de 22 currais, somando pelo menos 13 mil cabeças de gado. Nessas terras também eram lavrados grãos de arroz e feijão, além de hortas e pomares. Era feito ainda o plantio do algodão, utilizado na produção de vestimentas. O autor comenta, em um de seus estudos, como o ensino de ofícios se acentuava à medida que as fazendas jesuíticas cresciam, tornando necessária a mão-de-obra especializada, de modo que: 
[...] as artes mecânicas e a produção manufaturada surgiram em face do necessário suporte operacional às atividades do grande complexo autônomo que era a fazenda. [...] As oficinas alcançaram um nível de eficiência e qualidade tal que se transformaram em verdadeiras escolas de ofícios e um centro de produção fabril muito importante, exportando produtos raros na colônia (SANGENIS, 2014, p. 39).

Ainda de acordo com o autor, para dar veloz continuidade às atividades da terra, os jesuítas permitiam a concepção entre escravos, visando estabelecer um vasto número de trabalhadores. Pelo ano de 1768, já tinham se formado 430 famílias, traduzidas em mais de 1600 escravos. Diante das extensas necessidades, consequentes da larga expansão da rede educacional, os padres chegaram até mesmo a conduzir engenhos de açúcar, tornando-se proprietários de grandes canaviais. Nesse período, os lucros da fazenda do Rio de Janeiro chegavam 30 mil cruzados anualmente, sendo a quantia de 12 mil conferida ao reitor do colégio e o valor remanescente utilizado para o abastecimento de remédios, vinhos, panos, entre outros itens (SANGENIS, 2014).

Com impressionante domínio econômico, a Companhia de Jesus tornou-se a mais poderosa ordem religiosa do território brasileiro entre os séculos XVI e XVII, tendo suas riquezas avaliadas em mais de mil contos de reis. Entre os seus bens, os padres reuniam, "engenhos, canaviais, fazendas de criação de gado, lavouras de algodão, de fumo e de subsistência, prédios rústicos, imóveis urbanos, olarias, larga escravaria" (SANGENIS, 2014, p. 40).

Desse modo, em 1570, a redízima já havia se tornado parte irrelevante do financiamento da educação escolar promovida pelos jesuítas, que tinha garantido sua gratuidade. Além disso, o constante investimento permitiu o aprimoramento de seus cursos e métodos (MONLEVADE, 2012).

\section{Expulsão dos jesuítas e reformas Pombalianas - Financiamento a partir do Subsídio literário}

No Brasil, o êxito do projeto educativo dos jesuítas se evidenciou diante do número de instituições escolares erguidas no país. Até o ano de 1758, foram construídos dezessete Colégios, além de mais de duzentas escolas (MONLEVADE, 2012). Organizadas de acordo com os interesses da burguesia portuguesa, essas instituições acompanharam movimentos de apropriação econômica e de dominação política, determinados pelo regime de produção vigente (SOUSA; SALES, 2018). 
Responsáveis pela "formação de uma elite que iria subdirigir o território e manter-se no alto da hierarquia política, social e econômica" (MESQUIDA, 2013, p. 248) e pela bem sucedida quebra da resistência indígena (SILVA et al., 2016), os padres jesuítas terminaram por alcançar os objetivos iniciais do Estado Português. No entanto, de acordo com Mesquida (2013), a Companhia passou a ser vista como concorrente pela Corte, uma vez que o serviço prestado pelos nativos, que sempre foram protegidos pelos padres contra ofensivas escravagistas, era útil somente à Companhia, que fazia uso constante de sua força produtiva.

Detendo cerca de $25 \%$ do Produto Interno Bruto (PIB) brasileiro, a Companhia de Jesus, além de desagradar a Corte, passou a incomodar também os mercadores portugueses. Vendo seus negócios ameaçados, os comerciantes alegavam desvantagem diante dos privilégios dos jesuítas (MENEZES, 2005), que possuíam, em suas fazendas:

[...] ferraria, carpintaria, olaria, ourivesaria, tecelagem e até um estaleiro, localizado às margens do rio Guandu, para reparos em pequenos barcos. [...]. Delas saíam madeiras cortadas, tijolos, ladrilhos, telhas e ferragens para as construções da cidade e o levantamento de fortificações, bem como materiais para obras de várias espécies, inclusive as hidráulicas e as de abertura de caminhos (SANGENIS, 2014, p. 39).

O conflito de interesses entre a Coroa e a Companhia, além da cobiça das riquezas jesuíticas por parte dos portugueses, levou a atritos que chegaram ao seu ápice durante o governo do Marquês de Pombal, Sebastião José de Carvalho, ministro que decidiu pela expulsão dos religiosos (MONLEVADE, 2012).

Menezes (2005) aponta que o banimento dos jesuítas foi motivado por divergências entre o projeto de modernização da Coroa e os religiosos, que o desaprovavam e incitavam essa aversão também nos nativos, através dos seus sermões. Desse modo, o movimento, batizado de antijesuitismo, se deu principalmente porque os padres "representavam um obstáculo e fonte de resistência às tentativas de implantação da nova filosofia iluminista que se difundia rapidamente por toda a Europa" (SHIGUNOV NETO; MACIEL, 2008, p. 184).

Os motivos que levaram a expulsão da ordem jesuítica podem, portanto, segundo Shigunov Neto e Maciel (2008), ser classificados como: político, uma vez que os jesuítas, com seu amplo domínio econômico, passaram a representar um obstáculo para a modernização do Estado Português; e ideológico, já que "transformações 
sociais advindas do movimento lluminista e dos princípios liberais requeriam a formação de um novo homem, o homem burguês, o comerciante, e não mais o homem cristão" (SHIGUNOV NETO; MACIEL, 2008, p. 183). Assim, o Marquês de Pombal buscava instituir, nos domínios de Portugal, um novo modelo pedagógico, guiado por uma concepção política e economicamente centralizada (MORAIS; OLIVEIRA, 2012).

Confiscadas pela Coroa Portuguesa, as propriedades jesuíticas foram leiloadas, e os valores recolhidos utilizados para o pagamento de dívidas da Corte, que passava por um momento de forte crise e estagnação econômica (MENEZES, 2005). Abolindo as instituições escolares jesuíticas não apenas do território de Portugal, mas também de seus demais domínios, o alvará régio de 28 de junho de 1759 baniu, somente da colônia brasileira, mais de 500 padres. Apesar de retirar os jesuítas do cenário educacional, o alvará régio português não impediu a permanência das demais congregações religiosas, que continuaram com os processos de doutrinação nos territórios (CURY, 2018).

Fávero (2000) aponta que, no mesmo alvará régio que determinava o fim da educação jesuítica, Pombal indicou que artifícios a substituiriam, iniciando a chamada reforma dos estudos menores. Entre as mudanças, estava o novo posto de diretor geral dos estudos, que concedia a licença necessária para a atividade de ensino. A reforma previa ainda o impedimento da utilização de livros dos jesuítas pelos mestres, principiando assim a mudança de "uma escola que servia à fé, por uma que servia ao Estado" (FÁVERO, 2000, p. 98).

Ainda segundo o autor, o alvará régio introduziu as denominadas Aulas Régias, que, prestadas nas Escolas Menores, deveriam ser lecionadas de acordo com o método da Congregação do Oratório, publicado em 1752. Cada aula régia compunha uma determinada disciplina, que possuía um único professor, geralmente indicado por bispos e nomeado pelo rei, em cargo vitalício. Sem um currículo sistematizado ou duração determinada, as aulas régias eram independentes, e não dialogavam entre si (FÁVERO, 2000).

De acordo com Morais \& Oliveira (2012), do ano de 1759 a 1771, coube às Câmaras Municipais financiar a educação oferecida na Colônia. Com permissão para recolher recursos diretamente dos pais dos estudantes, esse molde de financiamento lembrava o da escola privada. Segundo Menezes (2005), apesar do recolhimento das quantias, o modelo acarretou graves dificuldades para a retribuição dos educadores. 
Essa deficiência nos pagamentos fez com que o número de professores se mantivesse baixo e, consequentemente, a oferta de aulas também era escassa.

Contudo, na Carta de Lei publicada em 6 de novembro de 1772, Pombal inaugurou uma nova etapa de suas reformas educacionais, criando o que seria 0 "primeiro sistema público de ensino do Ocidente" (MORAIS; OLIVEIRA, 2012, p. 84). Estabelecido em níveis, eram ofertadas, pelo sistema

[...] as aulas de Primeiras Letras (em que se aprendia a ler/escrever/contar e Doutrina Cristã) e as cadeiras do "secundário", que antecediam a universidade. Este segundo nível era dividido em Humanidades (Grego, Latim e Retórica) e Filosofia ou Ciências da Natureza (Química, Física e Botânica) (MORAIS; OLIVEIRA, 2012, p. 84).

Ao mesmo tempo que fundava instituições de ensino superior e estabelecia novas diretrizes para a educação responsável pela formação de futuros dirigentes, o Estado instituía também um modelo que focava no ensino profissional de atividades ligadas à produção (SOUSA; SALES, 2018). Delineando os primeiros traços do que posteriormente viria a se tornar a Educação profissionalizante, tal formação, direcionada somente às classes mais carentes, surgiu sob o argumento de que essa parte da população necessitava de trabalho para sobreviver e, para tanto, deveria aprender ofícios manuais (MORAIS, 2016).

Tal segregação, ao dividir indivíduos pela sua função social, estabeleceu a disparidade de classes que levou à histórica e persistente dicotomia da educação brasileira (SILVA et al., 2016), dividindo-a entre educação profissional, direcionada aos trabalhadores, e educação intelectual, destinada à aristocracia (SILVA; AMORIM, 2017).

O ensino profissionalizante, ofertado pela Coroa durante o período colonial, se dava a partir de necessidades imediatas. A indisponibilidade de mão-de-obra para tarefas específicas, como a restauração dos navios que sofriam danos durante as viagens entre o Brasil e Portugal, por exemplo, estimulava o ensino compulsório de ofícios como este (MORAIS, 2016).

De acordo com Sá et al. (2015, p. 9659), "o ensino dos ofícios era ministrado, geralmente, fora da escola, nos locais de trabalho, como, por exemplo, nos cais, nos hospitais, na marinha e nos arsenais militares." Desse modo, como 
esclarece Fonseca (1962, p. 424 apud MORAIS, 2016, p. 18), essa formação se dava em ambientes improvisados. Segundo o autor,

\begin{abstract}
A aprendizagem era feita pelo método da época, isto é, pelo princípio imitativo, em que os jovens se exercitavam nos ofícios vendo os oficiais trabalhar e reproduzindo aquilo que os mesmos executavam. Não havia ensino propriamente dito. Fazia-se com que os menores fossem entregues a certos mestres ou oficiais que lhes deviam revelar a arte que professavam [...]. Nenhuma espécie de instrução teórica era ministrada àqueles aprendizes. Davam-se-lhes, apenas, conhecimentos práticos, ou melhor, deixava-se que eles aprendessem o que viam fazer e repetiam.
\end{abstract}

Assim, essa modalidade de ensino não era amparada por qualquer política específica que tivesse em vista avanços ou melhorias. Isso acontecia principalmente devido à preeminência de escravos no país, que tornava desnecessário o investimento em escolas de artes mecânicas ou no refinamento dos métodos de transmissão do conhecimento (MORAIS, 2016).

Demonstrando sinais de incômodo com a relação entre a alta demanda por mão-de-obra qualificada e a pequena parcela de indivíduos escolarizados, o Estado criou, através da Carta Régia de 10 de novembro de 1772, o Subsídio Literário (MENEZES, 2005). Instituído pelo Marquês de Pombal, o imposto era atribuído ao financiamento das aulas régias, e tinha os valores arrecadados convertidos em salários para os mestres (CURY, 2018). O documento trazia, em seu $\S 2^{\circ}$ do art. 6은

\begin{abstract}
Mando que para a útil aplicação, do mesmo ensino público, em lugar das sobreditas coletas até agora lançadas a cargo dos povos, se estabeleça, como estabeleço o único imposto: a saber, nestes reinos e ilhas Madeira, Açores de um real em cada canastra de vinho e quatro réis em cada canada de aguardente; de 160 réis por pipa de vinagre; na América e na África: de um real em cada arretel de carne que se cortar no açougue; e nelas, e na Ásia, de dez réis em cada canada de aguardente das que se fazem nas terras, debaixo de qualquer nome que se the dê ou venha dar (PORTUGAL, 1772 apud CURY, 2018, p. 1220).
\end{abstract}

Surgiu, assim, "a primeira forma estatal de financiamento da educação pública no Brasil" (CURY, 2018, p. 1219). Encarregadas da coleta dos impostos, as Câmaras Municipais mantinham registros das quantias provenientes do tributo, e os enviava aos Ouvidores trimestralmente. Os Ouvidores, por sua vez, encaminhavam os registros, juntamente às receitas, ao Cofre Geral da Junta da Real Fazenda de 
cada capitania, que gerenciava os recursos e fornecia o ordenado aos professores (MORAIS; OLIVEIRA, 2012).

A receita provinda do imposto, além de mínima, não fornecendo o aporte financeiro necessário, era sonegada, ou mesmo utilizada para outras finalidades pelo Estado (VERALDO, 2009). Passando continuamente por processos fraudulentos, o imposto, que foi recolhido até o ano de 1816, chegou ao fim com recolhimentos que seriam insuficientes para pagar um número maior do que trinta educadores (MENEZES, 2005).

A educação escolar viu-se ainda mais desprovida de recursos estatais no governo de Dom João VI, que, no Decreto de 28 de Junho de 1821, tornou a educação livre e independente de licenças no país, desobrigando o Estado não apenas do seu financiamento, mas também de sua oferta (CURY, 2018). No documento, dispôs:

[...] atendendo a que não é possível desde já estabelecer, como convém, escolas em todos os lugares deste Reino por conta da Fazenda Pública; e querendo assegurar a liberdade que todo o cidadão tem de fazer o devido uso de seus talentos, não seguindo daí prejuízos públicos, decretam que da publicação deste em diante seja livre a qualquer cidadão o ensino e a abertura de Escolas de primeiras letras, em qualquer parte deste Reino, quer seja gratuitamente, quer por ajuste dos interessados, sem dependência de exame ou de alguma licença (PORTUGAL, 1821 apud CURY, 2018, p. 1221).

Com o citado decreto, o Estado se exime da responsabilidade de promover políticas de financiamento para a educação escolar no Brasil Colonial, demarcando ainda mais seu afastamento quando para investir na rede pública educacional (CURY, 2018).

O sistema de aulas régias, que existiu até o ano de 1834, teve como principal particularidade o difícil ingresso, uma vez que apenas uma pequena parte da população conseguiu acesso à educação nesse período, devido à sua baixa oferta (MENEZES, 2005). O pequeno número de mestres, decorrência direta da falta de recursos, se mostrou como um grande obstáculo para implementação das propostas introduzidas pelas reformas do Marquês de Pombal, o que se opunha ao constante investimento dos educadores jesuítas. Assim, é seguro dizer que as receitas provenientes do Subsídio Literário não foram satisfatórias para surtir qualquer efeito positivo sobre o financiamento da educação escolar no Brasil Colônia (MONLEVADE, 2012) que experimentou, desse modo, sua primeira queda de recursos (FÁVERO, 2000). 
Diante de todo o visto, pode-se afirmar que a trajetória da educação escolar no período colonial do Brasil foi marcada pela falta de grandes investimentos estatais. Ainda que a Coroa Portuguesa tenha subsidiado a chegada dos padres jesuítas e, no decorrer desse caminho, criado tributações para o financiamento educacional, estas medidas mostraram-se insuficientes, dado que a larga oferta da educação foi vista somente quando eram os jesuítas os responsáveis pelo seu financiamento. Durante o período colonial, foi possível também destacar os indícios primitivos de uma formação profissional, direcionada ao trabalho. Esses traços são realçados pelas ocasiões onde aqueles mais carentes recebiam, em oficinas, o ensino de artes manuais, em detrimento da formação escolarizada fornecida aos mais nobres.

\section{Considerações Finais}

Pelo exposto, percebe-se que a educação obteve recursos de diversas fontes durante o seu curso no período colonial do Brasil, indo desde doações até a criação de impostos específicos para o seu financiamento.

Num primeiro momento, foi a Coroa portuguesa a responsável por financiar, a partir de doações, a instalação e subsistência dos membros da Companhia de Jesus no território brasileiro, inicialmente incumbidos de catequizar os nativos. Esse acordo permaneceu de 1549 até 1564 , quando foi instituída a redízima, primeira tributação a arrecadar valores e os destinar para o financiamento da educação. Nesse período, foi possível identificar os primeiros indícios de uma educação profissional, voltada para o trabalho, visto que o processo de catequização dos jesuítas para com os nativos envolvia o ensino de ofícios manuais, que serviam aos propósitos dos padres.

Quando responsabilizados também pela educação da elite colonial, as receitas da redízima mostraram-se escassas, motivo pelo qual o padre Nóbrega elaborou o plano de autofinanciamento, que permitiu a larga expansão da rede educacional. Baseadas no cultivo e venda de produtos provindos da agricultura, as práticas tornaram a Companhia de Jesus a ordem religiosa mais rica presente no Brasil, revertendo a situação de baixos investimentos na educação.

Com as chamadas reformas Pombalianas, dadas após a expulsão dos jesuítas dos domínios de Portugal em 1759, coube às Câmaras Municipais a responsabilidade de financiar a educação. Foram colhidos, por um breve período, recursos dos pais dos alunos, lembrando o modelo da escola privada. 
Em 1772, com a instituição do primeiro sistema público de ensino, deu-se início ao sistema de aulas régias. Nesse período, foi possível observar, novamente, indícios de uma educação profissionalizante no sistema educativo, visto que, no ensino da classe colonial dominante, utilizavam-se técnicas que propiciavam uma formação intelectual, enquanto o ensino dos mais carentes era baseado na instrução de ofícios, registrando traços de uma dualidade educacional que ainda hoje persiste. Para o financiamento da educação, foi criado, neste período, o Subsídio Literário, imposto atribuído ao pagamento dos mestres. Em 1834, o sistema de aulas régias veio a fracassar, em grande parte devido à falta de recursos financeiros, o que impossibilitava a remuneração dos professores. Tal circunstância se opõe à que se via anteriormente, quando os jesuítas financiavam as atividades.

Durante o estudo de todo esse trajeto, que perdurou por três séculos, foi possível inventariar as medidas adotadas e os atores responsáveis pelo financiamento da educação no período colonial do Brasil, bem como apontar os primeiros indícios de uma educação profissionalizante. Concluímos, porém, ressaltando a necessidade de futuras pesquisas, que visem diminuir eventuais lacunas deixadas por este estudo.

\section{Referências Bibliográficas}

ALEGRE, Maria Sylvia Porto. Educação indígena colonial: ironias de um projeto. Mneme: Revista de Humanidades, Caicó, v. 15, n. 35, p. 87-110, out. 2015.

ALMEIDA, Wilson Ricardo Antoniassi de. A educação jesuítica no Brasil e o seu legado para a educação da atualidade. Revista Grifos, Chapecó, v. 23, n. 36/37, p. 117-126, 2014.

COSTA, Célio Juvenal; MENEZES, Sezinando Luiz. A educação no Brasil Colonial (1549-1759). In: ROSSI, Ednéia Regina; RODRIGUES, Elaine; NEVES, Fátima Maria (Orgs.). Fundamentos históricos da educação no Brasil, 2. ed. rev. e ampl. Maringá: Eduem, 2009. 168 p.

CURY, Carlos Roberto Jamil. Financiamento da Educação Brasileira: do subsídio literário ao FUNDEB. Educ. Real., Porto Alegre, v. 43, n. 4, p. 1217-1252, out. 2018.

FÁVERO, Leonor Lopes. Heranças: A Educação no Brasil Colônia. Revista da ANPOLL, São Paulo, v.1, n. 8, p. 87-102, jan./jun. 2000.

FERREIRA, Maria Aparecida dos Santos. O FUNDEF e o FUNDEB como política de financiamento para a valorização do magistério: efeitos na carreira e na remuneração dos professores da rede pública estadual de ensino do RN. 2014, 353 f. Tese (Doutorado em Educação) - Universidade Federal do Rio Grande do Norte, 
Natal, 2014.

Disponível

em: <https://repositorio.ufrn.br/jspui/bitstream/123456789/19286/1/FUNDEFeFUNDEBPol \%C3\%ADtica_Ferreira_2014.pdf>. Acesso em: 04 jul. 2020.

FERREIRA JR., Amarilio; BITTAR, Marisa. Artes liberais e ofícios mecânicos nos colégios jesuíticos do Brasil colonial. Rev. Bras. Educ., Rio de Janeiro, v. 17, n. 51, p. 693-716, dez. 2012.

LORENZ, Karl. Introdução à Pedagogia Jesuíta no Brasil Colonial. Educação Humanista e o Ratio Studiorum. Cadernos de História da Educação, Uberlândia, v. 17, n. 1, p. 25-50, jan./abr. 2018.

MENEZES, Janaina Specht da Silva. O financiamento da Educação Básica pública no Brasil: 500 anos de História. In: Seminário Nacional de Estudos e Pesquisas, 7., 2006, São Paulo. Anais [...]. Campinas: UNICAMP, 2006. Disponível em: <http://www.histedbr.fe.unicamp.br/acer_histedbr/seminario/seminario7/TRABALHO S/J/Janaina\%20specht\%20da\%20silva\%20menezes.pdf>. Acesso em: 04 jul. 2020.

MESQUIDA, Peri. Catequizadores de índios, educadores de colonos, Soldados de Cristo: formação de professores e ação pedagógica dos jesuítas no Brasil, de 1549 a 1759, à luz do Ratio Studiorum. Educ. rev., Curitiba, v. 29, n. 48, p. 235-249, jun. 2013.

MORAIS, Christianni Cardoso; OLIVEIRA, Cleide Cristina. Aulas régias, cobrança do subsídio literário e pagamento dos ordenados dos professores em Minas Gerais no período colonial. Educação em Perspectiva, Viçosa, v. 3, n. 1, p. 81-104, jan./jun. 2012.

MORAIS, Renant Araújo. O ensino de artes e ofícios no Brasil Colônia. Plures Humanidades, Ribeirão Preto, v. 17, n. 1, 2016.

NASCIMENTO, Maria Isabel Moura. Instituições escolares no Brasil colonial e imperial. Revista HISTEDBR on-line, Campinas, n. 28, p. 181-203, dez. 2007. Disponível <http://www.histedbr.fe.unicamp.br/navegando/artigos_frames/artigo_075.html> Acesso em 28 jun. 2020.

PIRES, Marília Freitas de Campos. O materialismo histórico-dialético e a Educação. Interface, Botucatu, v.1, n.1, p.83-94, ago. 1997.

SÁ, Helvécio Goulart Malta de et al. Antecedentes históricos do ensino profissional no Brasil nos períodos colonial e imperial. In: Congresso Nacional de Educação (EDUCERE), 12., 2015, Curitiba. Anais [...]. Curitiba: PUCPR, 2015, p. 9654-9668. Disponível em: <https://educere.bruc.com.br/arquivo/pdf2015/19479_10656.pdf>. Acesso em: 04 jul. 2020. 
SANGENIS, Luiz Fernando Conde. Controvérsias sobre a pobreza: franciscanos e jesuítas e as estratégias de financiamento das missões no Brasil colonial. Estud. hist., Rio de Janeiro, v. 27, n. 53, p. 27-48, jun. 2014.

SAVIANI, Dermeval. História das ideias pedagógicas no Brasil. 1. ed. Campinas: Autores Associados, 2019. 504 p. E-Book. ISBN 978-85-7496-426-3. Disponível em: $<$ https://books.google.com.br/books?id=a1-HDwAAQBAJ\&printsec=frontcover\&hl=pt$\mathrm{BR} \# \mathrm{v}=$ onepage \&q\&f=false>. . Acesso em: 29 jun. 2020.

SAVIANI, Dermeval. O trabalho como princípio educativo frente às novas tecnologias. In: FERRETI, C. J. et al. (Orgs.). Novas tecnologias, trabalho e educação. Petrópolis: Vozes, 1994. p. 147-164.

SHIGUNOV NETO, Alexandre; MACIEL, Lizete Shizue Bomura. O ensino jesuítico no período colonial brasileiro: algumas discussões. Educ. rev., Curitiba, v. 24, n. 31, p. 169-189, 2008.

SILVA, Carlos Daniel da. Educação Brasileira: as contradições deste processo histórico da Colonização à República. In: Congresso Nacional de Educação (EDUCERE), 12., 2015, Curitiba. Anais [...]. Curitiba: PUCPR, 2015, p. 14285-14301. Disponível em: <https://educere.bruc.com.br/arquivo/pdf2015/20026_9700.pdf>. Acesso em: 04 jul. 2020.

SILVA, Gleidson; AMORIM, Simone Silveira. Apontamentos sobre a educação no Brasil Colonial (1549-1759). Interações, Campo Grande, v. 18, n. 4, p. 185-196, out./dez. 2017.

SILVA, Shirley Macielle da et al. A educação jesuítica no Brasil Colônia e sua herança contemporânea. In: Congresso Nacional de Educação (CONEDU), 3., 2016, Natal. Anais [...]. Campina Grande: Realize, 2016. Disponível em: <http://www.editorarealize.com.br/artigo/visualizar/19784>. Acesso em: 04 jul. 2020.

SOUSA, Tássia Pinheiro de; SALES, Francisco José Lima. As políticas de Educação Profissional no Brasil e a qualificação dos trabalhadores. Revista Labor, Fortaleza, v. 1, n. 21, p. 98-118, jan./jun. 2018.

TOLEDO, Cézar de Alencar Arnaut de; RUCKSTADTER, Flávio Massami Martins. Estrutura e organização das Constituições dos jesuítas (1539-1540). Acta Scientiarum. Human and Social Sciences, Maringá, v. 24, n.1, p. 103-113, abr. 2008.

VERALDO, Ivana. A educação brasileira na segunda metade do século XVIII (17591822). In: ROSSI, Ednéia Regina; RODRIGUES, Elaine; NEVES, Fátima Maria (Orgs.). Fundamentos históricos da educação no Brasil, 2. ed. rev. e ampl. Maringá: Eduem, 2009. 168 p. 
VIANNA, Hélio. A educação no Brasil colonial. Revista Brasileira de Estudos Pedagógicos, Rio de Janeiro, v. 6, n. 18, p. 372-392, dez. 1945.

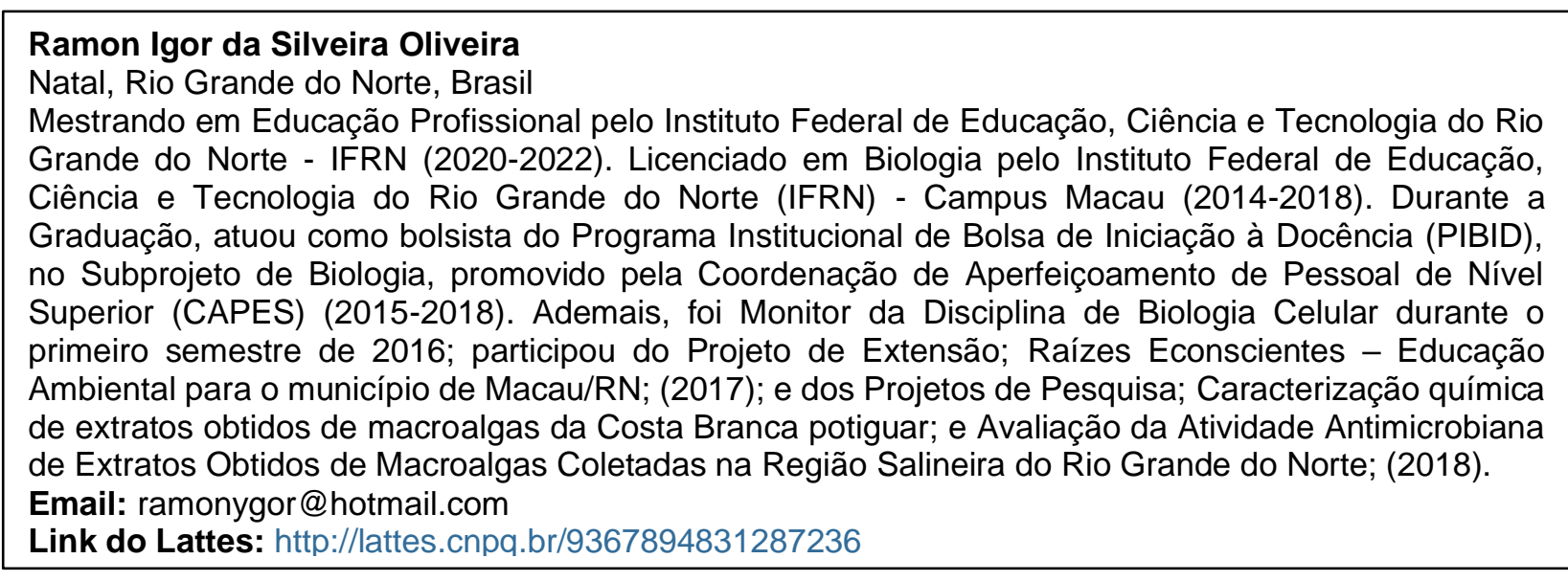

\section{Maria Aparecida dos Santos Ferreira.}

São Paulo de Potengi, Rio Grande do Norte, Brasil

Possui Licenciatura em Pedagogia pela Universidade do Estado do Rio Grande do Norte (1988), Especialização em Formação do Educador pela Universidade Estadual do Rio Grande do Norte (2002), Mestrado em Educação pela Universidade Federal do Rio Grande do Norte (2010) e Doutorado em Educação pela Universidade Federal do Rio Grande do Norte (2014). Atualmente é docente do Instituto Federal de Educação, Ciência e Tecnologia do Rio Grande do Norte, São Paulo do Potengi; Professora do Programa de Pós-Graduação em Educação Profissional (PPGEP/IFRN) a partir de 2017); e Coordenadora da Linha de Política e Práxis da Educação Profissional (2019).

Email: maria.santos@ifrn.edu.br

Link do Lattes: http://lattes.cnpq.br/2209638083101531

\section{Recebimento: $24 / 07 / 2020$}

Aprovação: 12/10/2020

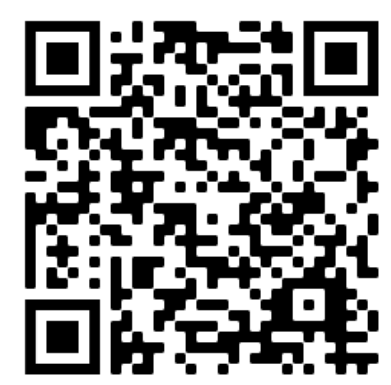

\section{Q.Code}

\section{Editores-Responsáveis}

Dr. Enéas de Araújo Arrais Neto, Universidade Federal do Ceará, UFC, Ceará, Brasil

Dr. Sebastien Pesce, Universidade de Orléans, França 